\title{
Polyamines Counteract Carbonate-Driven Proteasome Stalling in Alkaline Conditions
}

\author{
Anna A. Kudriaeva ${ }^{1}$, George A. Saratov ${ }^{1,2}$, Alena N. Kaminskaya ${ }^{1}$, Vasiliy I. Vladimirov ${ }^{3}$, \\ Petro Yu Barzilovich ${ }^{1}$ and Alexey A. Belogurov Jr. ${ }^{1,4, *}$ \\ 1 Shemyakin-Ovchinnikov Institute of Bioorganic Chemistry, Russian Academy of Sciences, \\ 117997 Moscow, Russia; anna.kudriaeva@gmail.com (A.A.K.); saratovgosha@gmail.com (G.A.S.); \\ kaminskayaan@mail.ru (A.N.K.); pjetro@yandex.ru (P.Y.B.) \\ 2 Phystech School of Biological and Medical Physics, Moscow Institute of Physics and Technology \\ (National Research University), 141701 Dolgoprudny, Russia \\ 3 Pushchino Branch of Shemyakin-Ovchinnikov Institute of Bioorganic Chemistry, \\ Russian Academy of Sciences, 142290 Pushchino, Russia; vasiliy.i.vladimirov@gmail.com \\ 4 Faculty of Fundamental Medicine, Lomonosov Moscow State University, 119991 Moscow, Russia \\ * Correspondence: belogurov@ibch.ru
}

Received: 22 October 2020; Accepted: 16 November 2020; Published: 24 November 2020

\begin{abstract}
Cancer cells tend to increase intracellular $\mathrm{pH}$ and, at the same time, are known to intensively produce and uptake polyamines such as spermine. Here, we show that various amines, including biogenic polyamines, boost the activity of proteasomes in a dose-dependent manner. Proteasome activity in the classical amine-containing buffers, such as 2-(N-morpholino)ethanesulfonic acid (MES), Tris, (4-(2-hydroxyethyl)-1-piperazineethanesulfonic acid (HEPES), glycylglycine, bis-Tris propane, and bicine, has a skewed distribution with a maximum at $\mathrm{pH}$ of 7.0-8.0. The activity of proteasomes in buffers containing imidazole and bis-Tris is maintained almost on the same level, in the $\mathrm{pH}$ range of 6.5-8.5. The third type of activation is observed in buffers based on the amino acids arginine and ornithine, as well as the natural polyamines spermine and spermidine. Proteasome activity in these buffers is dramatically increased at $\mathrm{pH}$ values greater than 7.5. Anionic buffers such as phosphate or carbonate, in contrast, inhibit proteasome activity during alkalization. Importantly, supplementation of a carbonate-phosphate buffer with spermine counteracts carbonate-driven proteasome stalling in alkaline conditions, predicting an additional physiological role of polyamines in maintaining the metabolism and survival of cancer cells.
\end{abstract}

Keywords: proteasome; polyamine; spermine; intracellular alkalization; activation; carbonate; inhibition

\section{Introduction}

Intracellular $\mathrm{pH}$ adjustment plays a crucial role in the metabolism and survival of the mammalian cell, as the activity of the majority of enzymes significantly depends on its value [1]. Essentially, cells from all types of mammalian tissues produce acid because of $\mathrm{CO}_{2}$ and lactic acid, generated by mitochondrial respiration and fermentative metabolism, respectively [2,3]. For almost a century, it has been known that cancer cells reorganize their metabolism in accord with the Warburg effect $[4,5]$. Oxygen depletion, together with genetic and epigenetic changes [6], shifts the metabolism of the cancer cells toward a more glycolytic phenotype [7], characterized by an exacerbated output of lactic acid [2]. Lactic acidosis, a high-lactate concentration with an acidic intracellular $\mathrm{pH}$, significantly enhances the survival of cancer cells under a lack of glucose. G1/G0 phase arrest, induction of autophagy, and inhibition of apoptosis are directly associated with lactic acidosis-mediated resistance to glucose 
deprivation. The high-lactate concentration, lactosis, with weak basic $\mathrm{pH}$, has a pronounced effect on cell survival during glucose starvation [8].

Acidification of the extracellular milieu and concomitant intracellular alkalization of the cytoplasm are highly common for tumor cells [9]. Extracellular pH in tumors is typically lower (6.5-6.9) than in normal tissue (7.2-7.5) [10]. Activation of various plasma membrane transporters and acid efflux proteins that control $\mathrm{pH}$ homeostasis [11], including monocarboxylate transporters, carbonic anhydrases, and $\mathrm{Na}^{+}-\mathrm{H}^{+}$exchangers, promotes intracellular alkalization [12]. This reverse $\mathrm{pH}$ gradient is associated with tumor aggressiveness, i.e., proliferation, invasion, metastasis, and treatment resistance [2,9,13-16]. Alkalization of the tumor's extracellular $\mathrm{pH}$ inhibits carcinogenesis [15], whereas mathematical modeling suggests that systemic buffers [17] with pKa 7.0 [18] may be used in order to accomplish such a pH shift. It is expected that bicarbonate shifts the intratumoral metabolism from lactic acidosis to lactosis and thus inhibits tumor growth and enhances the necrosis of cancer cells [19].

The natural polyamines spermidine and spermine are polycations with three and four amine groups, respectively. Almost every living cell contains polyamines in up to millimolar concentrations [20]. Rapidly growing cells activate the synthesis of polyamines from arginine and s-adenosylmethionine; spermine and spermidine are formed from 1,4-diaminobutane (putrescine). The biosynthesis of putrescine may be driven via classical and alternative pathways. In the classical pathway, urea and carbon dioxide are removed from arginine by arginase and ornithine decarboxylase (ODC), while the biochemistry of the alternative pathway includes the removal of carbon dioxide by arginine decarboxylase and, further, removal of urea by agmatinase [21]. Polyamines are involved in the crucial cellular processes closely linked to cell growth and differentiation, such as DNA synthesis and stability, regulation of transcription, protein phosphorylation, and ion channel regulation [22-24]. The concentration of polyamines, as well as the gene expression and activity of the enzymes involved in polyamine biosynthesis, especially ODC, is higher in tumors in comparison with the normal surrounding tissues [25-29]. Polyamine levels are increased in the blood and urine of patients with cancer and, in addition, the concentration of polyamines is positively correlated with poor prognosis [30].

Previously, it was shown that polyamines may increase the activity of enzymes, such as $\alpha$-chymotrypsin [31], and act like chemical chaperones [32]. In contrast, proteins enriched with basic amino acids such as arginine and lysine may directly bind proteasomes $[33,34]$ and are capable of further translocation into the proteolytic chamber $[35,36]$. Here, we investigate how the alkalization and increased concentration of polyamines may modulate the activity of proteasome, a part of the ubiquitin proteasome system (UPS), which specifically degrades thousands of intracellular proteins. The UPS consists of hundreds of ubiquitin ligases [37], conjugating the small protein ubiquitin with a substrate, which is further recognized and degraded by proteasome particles [38]. Proteasomes are absolutely necessary for cell functioning; moreover, their activity follows the overall cell metabolism. Inhibition of proteasomes in rapidly growing tumor cells is regarded as an effective therapeutic intervention during cancer [39]. Several classes of small molecules, including denaturing reagents (e.g., SDS), lipids, and peptides, namely those with the $\mathrm{HbYX}$ motif, were shown to activate the proteasome at relatively high concentrations (reviewed in [40]). Previously, it was reported that polylysine at $100 \mu \mathrm{M}$ [41] and other polycationic substances, including polyarginine, protamine, and histone H1 [42], activated the $20 \mathrm{~S}$ proteasome and the bacterial ATP-dependent protease Hs1VU [43]. Herein, we show that polyamines, in contrast to anionic buffers, significantly increase proteasome activity in a $\mathrm{pH}$ - and concentration-dependent manner in vitro. This observation may be a step forward in the understanding of the interplay among polyamines, proteasomes, and the carbonate-driven alkalization of cancer cells observed in vivo. 


\section{Materials and Methods}

\subsection{Materials}

Fluorogenic proteasome substrates were purchased from UBPbio (Aurora, IL, USA). The other solvents and chemicals were of reagent grade and acquired from either Merck KGaA (Darmstadt, Germany) or Helicon (Moscow, Russian Federation).

\subsection{Purification of Proteasomes from Bovine Liver}

The proteasome samples were prepared according to the protocol described in [33]. A bovine liver was mechanically homogenized in a hypotonic lysis buffer containing $10 \mathrm{mM}$ Tris- $\mathrm{HCl}(\mathrm{pH} 7.9), 1.5 \mathrm{mM}$ $\mathrm{MgCl}_{2}, 1 \mathrm{mM}$ ATP, and $10 \mathrm{mM} \mathrm{KCl}$. Furthermore, $2.0 \mathrm{mM}$ DTT, 0.025\% digitonin (MilliporeSigma, Burlington, MA, USA), $1.0 \mathrm{mM}$ phenylmethylsufonyl fluoride, and $0.1 \% \mathrm{~N}$-dodecyl b-D-maltoside were added. The prepared liver homogenate was subjected to 20 cycles of high-pressure homogenization (10 cycles at 350 bar and 10 cycles at 1000 bar, with an APV 2000 homogenizer (SPX Flow, Charlotte, NC, USA) ) and further incubated for $30 \mathrm{~min}$ on ice. Cell debris was removed by centrifugation at $30,000 \times g$ for $30 \mathrm{~min}$ at $4{ }^{\circ} \mathrm{C}$. The $\mathrm{S} 30$ cytoplasmic extract was supplemented with a purification buffer to $1 \times$ concentration (50 mM Tris- $\mathrm{HCl}$ (pH 7.0), $50 \mathrm{mM} \mathrm{KCl}, 10 \mathrm{mM} \mathrm{MgCl}, 1 \mathrm{mM}$ ATP, and $10 \mathrm{mM}$ $\beta$-glycerophosphate) from a $10 \times$ stock, followed by the addition of sucrose powder at a concentration of $20 \%(w / v)$. The extract was incubated at room temperature on a magnetic stirrer for $1 \mathrm{~h}$ and further centrifuged at $30,000 \times g$ for $30 \mathrm{~min}$ at $4{ }^{\circ} \mathrm{C}$. The clarified extract was subjected to differential precipitation with polyethylene glycol (PEG) with a mean molecular weight (MW) 400 (PEG400). PEG400 was added at a concentration of $20 \%(v / v)$ to the extract under stirring at $4{ }^{\circ} \mathrm{C}$ and then incubated for $20 \mathrm{~min}$. The precipitated proteins were centrifuged at $30,000 \times g$ for $30 \mathrm{~min}$ at $4{ }^{\circ} \mathrm{C}$. The supernatant was then precipitated by raising the concentration of the PEG400 to $30 \%(v / v)$ as described above. The precipitate, which contained the $26 \mathrm{~S}$ and $20 \mathrm{~S}$ proteasomes, was recovered by centrifugation at $30,000 \times g$ for $30 \mathrm{~min}$ at $4{ }^{\circ} \mathrm{C}$. The pellet was resuspended in a buffer for ion-exchange chromatography that contained $10 \mathrm{mM}$ Tris- $\mathrm{HCl}$ (pH 7.5), $200 \mathrm{mM} \mathrm{NaCl}, 1 \mathrm{mM}$ ethylenediaminetetraacetic acid (EDTA), $1 \mathrm{mM}$ dithiothreitol (DTT), $1 \mathrm{mM}$ ATP, and 10\% glycerol. After centrifugation at $30,000 \times \mathrm{g}$ for $30 \mathrm{~min}$ at $4{ }^{\circ} \mathrm{C}$ to remove the insoluble material, the extracts were subjected to ion-exchange chromatography utilizing Q-sepharose resin (with a 200-600 mM NaCl gradient). Fractions containing 20S and/or 26S proteasomes were identified according to the rate of Suc-Leu-Leu-Val-Tyr-aminomethylcoumarin (Suc-LLVY-AMC) hydrolysis in the presence or absence of $0.02 \%$ SDS. The selected fractions were pooled and precipitated by the addition of $40 \%(v / v)$ PEG400. Purified 26S and 20S proteasomes were reconstituted in a buffer containing $25 \mathrm{mM}$ Tris- $\mathrm{HCl}$ (pH 7.5), $1 \mathrm{mM}$ DTT, 5 mM MgCl $2,1 \mathrm{mM} \mathrm{ATP,} \mathrm{and} \mathrm{10 \%} \mathrm{glycerol.}$

\subsection{Measurement of the Peptidase Activity of Proteasomes}

The peptidase activity was determined with $0.5 \mu \mathrm{g} 20 \mathrm{~S}$ or $0.15 \mu \mathrm{g} 26 \mathrm{~S}$ proteasome incubated with $20 \mu \mathrm{M}$ of the fluorogenic substrate Suc-LLVY-AMC, Ac-Arg-Leu-Arg-aminomethylcoumarin (Ac-RLR-AMC), or Ac-Gly-Pro-Leu-Asp-aminomethylcoumarin (Ac-GPLD-AMC) (excitation wavelength of $380 \mathrm{~nm}$ and an emission wavelength of $440 \mathrm{~nm}$ ) in a volume of $100 \mu \mathrm{L}$ by a microplate reader (Varioscan Flash, Thermo Fisher Scientific, Waltham, MA, USA) at $37^{\circ} \mathrm{C}$. The buffer used for measurement of the activity of the proteasomes contained $25 \mathrm{mM}$ of an appropriate buffer at various pH levels, $1 \mathrm{mM}$ ATP, $1 \mathrm{mM}$ DTT, and $5 \mathrm{mM} \mathrm{MgCl}_{2}$. The $\mathrm{pH}$ of all buffers was adjusted at $37^{\circ} \mathrm{C}$, similar to the temperature used during the measurement of proteasome activity.

\subsection{In Vitro Ubiquitination and Proteasome Hydrolysis}

In Vitro ubiquitination was performed as follows: E1 (2 $\mu \mathrm{g})$ (Addgene \#63571) obtained according to [44] was mixed with $\mathrm{UbcH5c}(4 \mu \mathrm{g})$ (Addgene \#12643) obtained according to [45], ubiquitin (20 $\mu \mathrm{g})$, and Ub-TagGFP2 $(4 \mu \mathrm{g})$. The pET22-based plasmid coding for the Ub-TagGFP2-His 6 was generated by the overlap PCR utilizing the pTagGFP2-C vector (Evrogen, Moscow, Russia) as a matrix. Two terminal 
glycine residues in the ubiquitin sequence were substituted by valine in order to enhance resistance toward deubiquitination enzymes. The Ub-TagGFP2 was expressed in Escherichia coli (BL21(DE3) strain) and further purified by immobilized metal affinity chromatography (IMAC). The reaction was incubated at $37^{\circ} \mathrm{C}$ overnight in a buffer containing $20 \mathrm{mM}$ phosphate buffer ( $\left.\mathrm{pH} 8.0\right), 100 \mathrm{mM} \mathrm{NaCl}, 5 \mathrm{mM} \mathrm{MgCl}$, $3 \mathrm{mM}$ ATP, and $1 \mathrm{mM}$ DTT. The final volume of the reaction was $65 \mu \mathrm{L}$. Furthermore, $5 \mu \mathrm{L}$ from the in vitro ubiquitination reaction was supplemented with a final concentration of $20 \mathrm{mM}$ phosphate buffer ( $\mathrm{pH} 7.5$ or 8.5), $100 \mathrm{mM} \mathrm{NaCl}, 5 \mathrm{mM} \mathrm{MgCl}$, $3 \mathrm{mM}$ ATP, $1 \mathrm{mM}$ DTT, purified 26S proteasome (10 $\mu \mathrm{g})$, and spermine $(10 \mathrm{mM})$. The reaction volume was adjusted to $20 \mu \mathrm{L}$. The reaction was incubated at $37^{\circ} \mathrm{C}$ overnight.

\subsection{Data Analyses}

Statistical analyses were performed with SigmaPlot software (Systat Software, San Jose, CA, USA), utilizing unpaired $t$-tests. Any $p$-values $<0.05$ were taken as significant. The data were fitted to a polynomial square of an exponential or Gauss function.

\section{Results and Discussion}

\subsection{Four Types of $p H$-Dependent Proteasome Activation by Amines}

Proteasomes may exist in two basic states, namely as a core particle (20S) or as 20S capped with a $19 S$ regulatory particle (26S). Purified samples of the $20 S$ and $26 S$ proteasomes from the bovine liver were analyzed by polyacrylamide gel electrophoresis in the denaturing (Figure 1a) and native (Figure $1 b$ ) conditions. Activity of the $26 \mathrm{~S}$ proteasome samples was inhibited in the presence of $0.02 \%$ SDS; both proteasomes were completely inhibited in presence of specific inhibitor MG132 (Figure 1c). The 20S proteolytic core has chymotryptic-, tryptic-, and caspase-like activities; the former is regarded as the most crucial for protein degradation [46]. We therefore firstly measured the chymotryptic activity of the purified bovine $20 \mathrm{~S}$ and $26 \mathrm{~S}$ proteasomes at a $\mathrm{pH}$ range of $6.5-8.5$ in the various (poly)amine buffer systems. In order to estimate the direct effect of amines on proteasomes, the $\mathrm{pH}$ in the buffer system was maintained by the same amine.
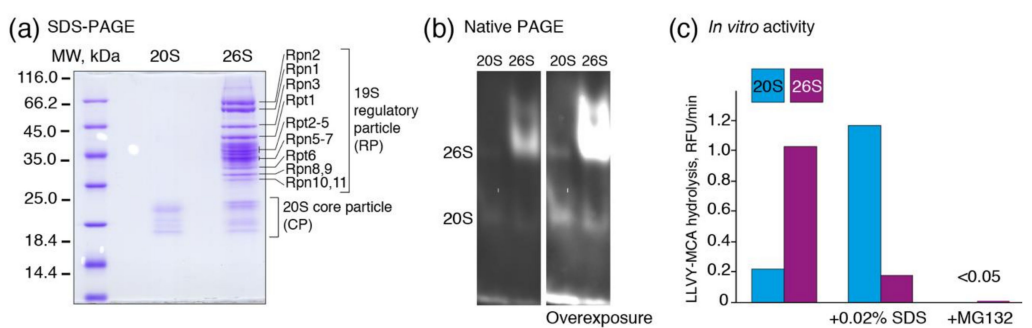

Figure 1. (a) The purified 20S $(1.5 \mu \mathrm{g})$ and $26 \mathrm{~S}(5.0 \mu \mathrm{g})$ proteasomes were subjected to polyacrylamide gel electrophoresis and further stained with Coomassie blue R250. Subunits of the 19S regulatory particle and the molecular weight marker are indicated. $(\mathbf{b}, \mathbf{c})$ The activity of $20 \mathrm{~S}$ and $26 \mathrm{~S}$ proteasomes was analyzed by native PAGE further saturated with Suc-LLVY-AMC (b) or measured in the presence or absence of $0.02 \%$ SDS and the proteasome inhibitor MG132 (c).

The profile of proteasome activity in the classical amine-containing buffers such as MES, Tris, HEPES, glycylglycine, bicine, and bis-Tris propane has a skewed distribution with a maximum at pH of 7.0-7.5 (Figure 2a). Meanwhile, buffers containing imidazole and bis-Tris maintained proteasome activity almost on the same level within the $\mathrm{pH}$ range studied (Figure $2 \mathrm{~b}$ ). The third type of activation was observed in the buffers based on the amino acids arginine and ornithine and the natural polyamines spermine (Spm) and spermidine (Spd). The activity of proteasomes in these buffers was dramatically increased at $\mathrm{pH}$ values greater than 8.0 (Figure 2c). Additionally, we studied synthetic branched polyamines (bPEI) with a molecular weight ranging from 0.6 to $1.8 \mathrm{kDa}$. These buffer systems revealed a fourth type of activation, which is characterized by a prolonged activity curve with saturation at a $\mathrm{pH}$ level $>8.0$ (Figure $2 \mathrm{~d}$ ). There was no evident correlation of activation type with either the presence 
of a primary, secondary, or tertiary amine group; nonetheless, the activity of proteasomes reached its maximum near the $\mathrm{pK} a$ value of the buffer system. The activity profile of the $20 \mathrm{~S}$ proteasome in almost all buffers followed that of 26S. In the case of a "skewed distribution", the maximum activity of the $20 \mathrm{~S}$ proteasome was shifted by half of a pH unit toward the alkaline area (Figure 2a).
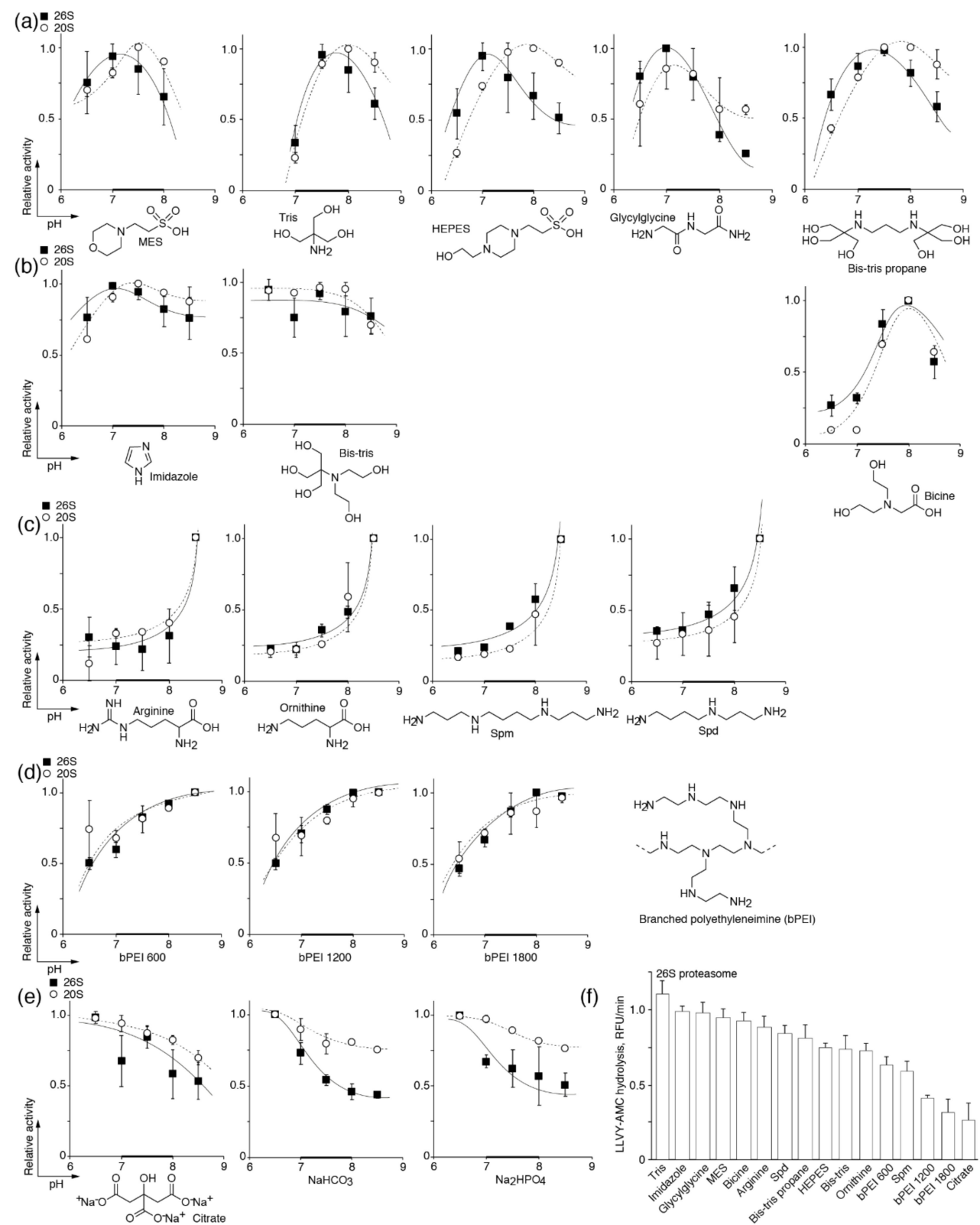

Figure 2. The $\mathrm{pH}$ dependence of the proteasomal chymotrypsin-like peptidase activity in different buffers containing (poly)amines (a-d) and anionic buffers (e). The skewed distribution (a), pH-independent (b), bursting (c) and progressive (d) types of activation are shown. Activity levels of the 26S ( $\square$ ) and 20S (O) proteasomes were measured using succinyl-Leu-Leu-Val-Tyr-7-amido-4-methylcoumarin (Suc-LLVY-AMC) at $25 \mathrm{mM}$ of each buffer system. Relative activity was calculated as the ratio of activity at a distinct $\mathrm{pH}$ to the maximal activity within the tested $\mathrm{pH}$ range. (f) Absolute activity of the $26 \mathrm{~S}$ proteasome in different buffers at the optimal $\mathrm{pH}$ value for each buffer system. The data represent the average and standard deviation (error bars) from four independent measurements. Natural polyamines (Spm, Spd) and branched polyamines (bPEI) were used at a concentration of $5 \mathrm{mM}$; all other buffers were at $25 \mathrm{mM}$. The data were fitted to a polynomial square of an exponential or Gauss function. The physiologically relevant $\mathrm{pH}$ range is shown by a bold line. 
The anionic buffer systems, such as citrate, carbonate, and phosphate, inhibited the activity of the proteasomes at an increased $\mathrm{pH}$ (Figure 2e). The activity of the $20 \mathrm{~S}$ proteasome was less affected by an increase in the $\mathrm{pH}$ value in the anionic buffers in comparison with the $26 \mathrm{~S}$ proteasome, which means that inhibition of $26 \mathrm{~S}$ may occur due to the rearrangement of the $19 \mathrm{~S}$ subparticle or partial dissociation of the $26 \mathrm{~S}$ proteasome to $20 \mathrm{~S}$ and 19S. The absolute activity of the $26 \mathrm{~S}$ proteasome in different buffers at the optimal $\mathrm{pH}$ value for each buffer system is shown in Figure 2f. As the $26 \mathrm{~S}$ and $20 \mathrm{~S}$ proteasomes are more or less similarly affected by amines and the $\mathrm{pH}$ value, we suggest that the activation of proteasomes is rather caused by their influence on the catalytic core particle.

Previously, it was shown that histone H3 significantly enhances 20S-mediated degradation of the oxidized B-chain of insulin in terms of the cleaving bonds, mainly after acidic and branched chain amino acids, i.e., positive allosteric activation of the caspase- and chymotrypsin- but not trypsin-like activities [47]. Indeed, measurement of the caspase- and trypsin-like activities of proteasomes in the buffers based on HEPES, imidazole, and the natural polyamines Spm and Spd at different $\mathrm{pH}$ levels (Figure 3) revealed that the caspase-like activity of the $26 \mathrm{~S}$ proteasome follows the profile of the chymotrypsin-like activity in all buffers. The trypsin-like activity was increased, similar to the caspaseand chymotrypsin-like activities in the Spm- and Spd-based buffers. In the HEPES and imidazole buffers, the trypsin-like activity of proteasomes has its own profile, with saturation at $\mathrm{pH}$ values more than 7.5-8.0, as was reported previously [48].

(a)

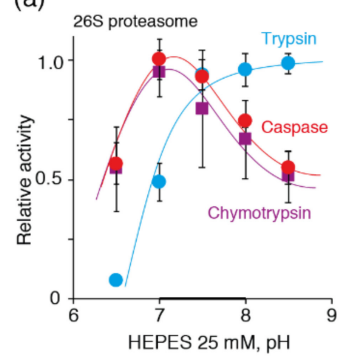

(b)

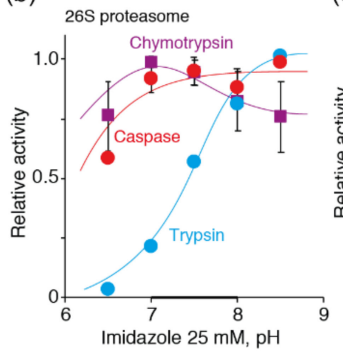

(c)

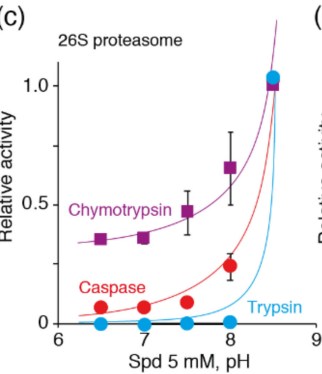

(d)

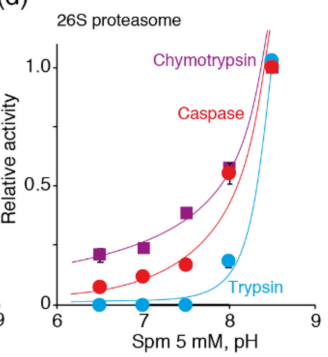

Figure 3. The $\mathrm{pH}$ dependence of the proteasomal chymotrypsin-like (violet), trypsin-like (blue), and caspase-like (red) peptidase activities in the buffers containing HEPES (a), imidazole (b), spermidine (c), and spermine (d). Activity of the $26 \mathrm{~S}$ proteasome was measured using Suc-LLVY-AMC (chymotrypsin-like), Ac-RLR-AMC (trypsin-like) or Ac-GPLD-AMC (caspase-like) fluorogenic substrates at $25 \mathrm{mM}$ of the HEPES and imidazole buffer systems and $5 \mathrm{mM}$ of the spermidine and spermine buffer systems. Relative activity was calculated as the ratio of activity at a distinct $\mathrm{pH}$ to the maximal activity within the tested $\mathrm{pH}$ range. The data represent the average and standard deviation (error bars) from four independent measurements. The data were fitted to a polynomial square of an exponential or Gauss function. The physiologically relevant $\mathrm{pH}$ range is shown by a bold line.

\subsection{Polyamines Counteract Carbonate-Driven Proteasome Stalling in Alkaline Conditions}

We next investigated if polyamines, like Spm, may increase the activity of proteasomes in the presence of carbonate. To this end, we firstly tested various concentrations of Spm at different $\mathrm{pH}$ levels, ranging from 6.5 to 8.5 (Figure 4a). Maximal activity of the26S proteasome was observed at a Spm concentration of $3 \mathrm{mM}$ and a $\mathrm{pH}$ of 8.0-8.5. Interestingly, a rise in the concentration of imidazole in the same $\mathrm{pH}$ range did not show any maximum in the activity profile of the $26 \mathrm{~S}$ proteasome (Figure $4 \mathrm{~b}, \mathrm{c}$ ), suggesting that polyamines, in contrast to the other amines, may inhibit the activity of the $26 \mathrm{~S}$ proteasome at high concentrations. Furthermore, the $25 \mathrm{mM}$ carbonate-phosphate buffer at a ratio of 24:1, imitating physiologically relevant cellular conditions, was supplemented with $10 \mathrm{mM} \mathrm{Spm}$, providing half of the maximal activation rate [49]. Proteasome activity was measured at different $\mathrm{pH}$ levels in this buffer, as well as separately in the carbonate-phosphate and Spm buffers (Figure 4d). The addition of polyamines to the carbonate-phosphate buffer preserved the activity of the $26 \mathrm{~S}$ proteasome at an alkaline $\mathrm{pH}$, suggesting that Spm compensates for carbonate-driven proteasome inhibition. 

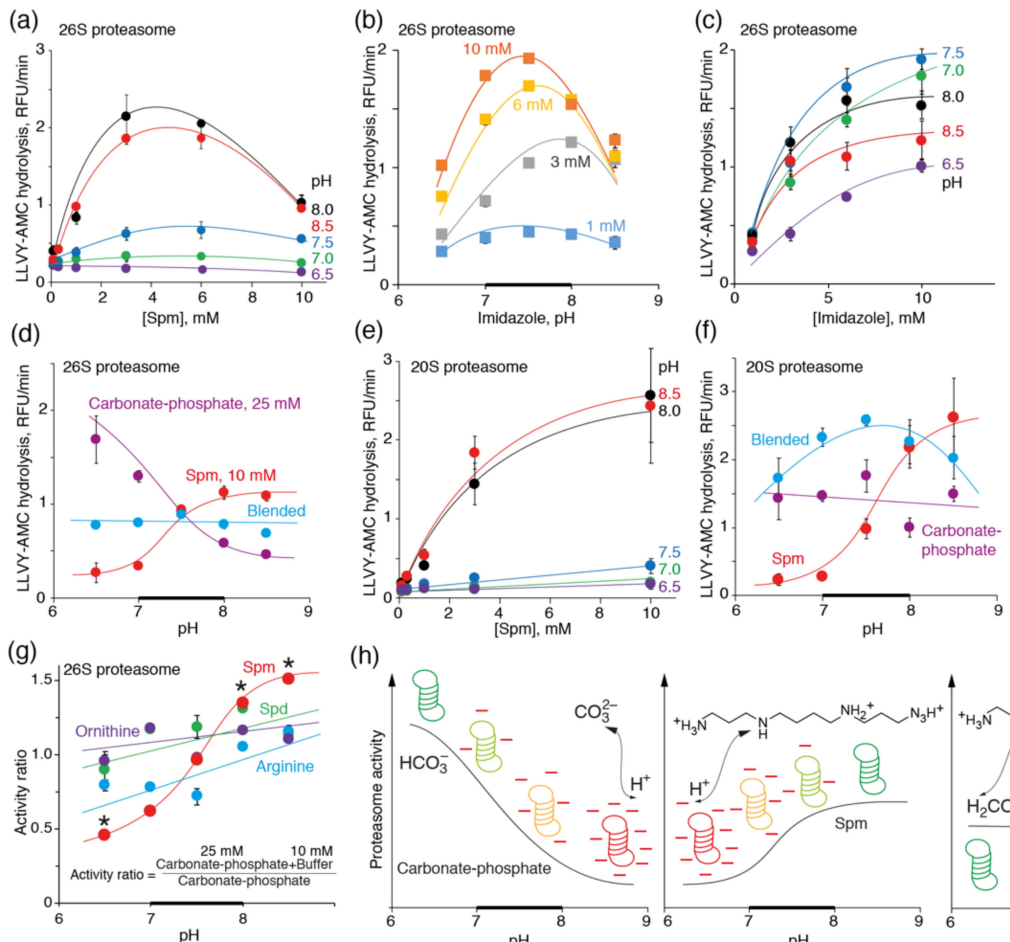

(h)

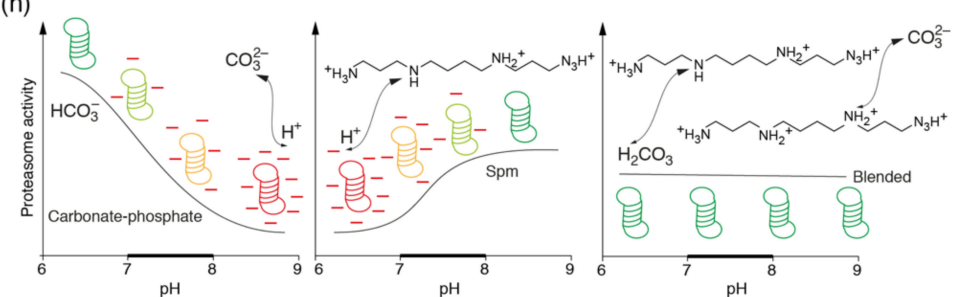

(i)

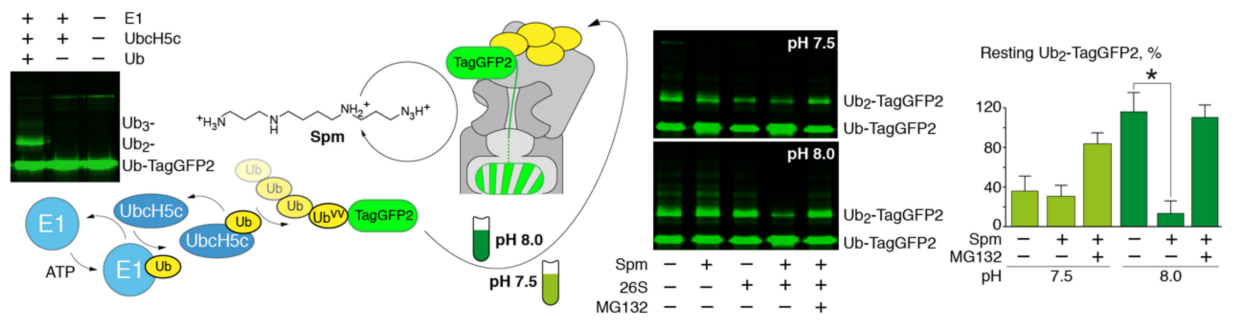

Figure 4. Spermine enhances the proteasomal chymotrypsin-like peptidase activity in a $\mathrm{pH}$-dependent manner and counteracts carbonate-driven proteasome stalling at an alkaline $\mathrm{pH}$. Chymotrypsin-like activity of the $26 \mathrm{~S}(\mathbf{a}, \mathbf{d})$ or $20 \mathrm{~S}(\mathbf{e}, \mathbf{f})$ proteasomes was measured at different $\mathrm{pH}$ and Spm concentrations $(\mathbf{a}, \mathbf{e})$ or at different $\mathrm{pH}$ in the amine buffer systems $(\mathbf{d}, \mathbf{f})$ containing $25 \mathrm{mM}$ carbonate-phosphate (24:1) (violet), $10 \mathrm{mM}$ Spm (red) or their mixture (cyan). (b,c) The pH dependence of the proteasomal chymotrypsin-like peptidase activity in the buffers containing various concentrations of imidazole at different $\mathrm{pH}$. Activity of the $26 \mathrm{~S}$ proteasome was measured using Suc-LLVY-AMC at the indicated concentrations of imidazole and $\mathrm{pH}$ values. The data represent the average and standard deviation (error bars) from four independent measurements. (g) Ratio of the chymotrypsin-like activity of the 26S proteasome measured in the $25 \mathrm{mM}$ carbonate-phosphate buffer supplemented with $10 \mathrm{mM}$ arginine (blue), ornithine (violet), Spd (green) or Spm (red) to the activity of the $26 \mathrm{~S}$ proteasome measured in the $25 \mathrm{mM}$ carbonate-phosphate buffer. Asterisks denote a statistically significant difference. The data were fitted to a polynomial square of an exponential or Gauss function and are shown as means \pm SD (error bars) from triplicate determinations. (h) Deprotonation of the $26 \mathrm{~S}$ proteasome by carbonate ions at an alkaline $\mathrm{pH}$ or by Spm at a neutral $\mathrm{pH}$ leads to proteasome inhibition. Simultaneous exposure of the $26 \mathrm{~S}$ proteasome to Spm and carbonate results in proton transfer between bicarbonate and Spm at a neutral $\mathrm{pH}$ and protonation of carbonate ions by protons from Spm at an alkaline $\mathrm{pH}$. The presence of Spm as a proton donor at alkaline $\mathrm{pH}$ protects the proteasome and thus preserves its activity. (i) Ub-TagGFP2 was ubiquitinated in vitro by a reconstituted $\mathrm{E} 1-\mathrm{UbcH} 5 \mathrm{c}$ cascade and further mixed with the $26 \mathrm{~S}$ proteasome at various $\mathrm{pH}$ levels in the presence or absence of Spm. Bars on the right represent the percentage of the di-ubiquitinated TagGFP2 hydrolyzed by the $26 \mathrm{~S}$ proteasome compared with the control sample. Standard deviations are shown. The physiologically relevant $\mathrm{pH}$ range is shown by a bold line. 
The activity of the 20S proteasome upon addition of various concentrations of Spm constantly increased and no maximum was observed (Figure 4e). Similar to the $26 \mathrm{~S}$ proteasome, maximal activation of $20 \mathrm{~S}$ proteasome was observed at $\mathrm{pH}$ 8.0-8.5. Profiling of the activity of $20 \mathrm{~S}$ proteasome in the carbonate-phosphate buffer supplemented with $10 \mathrm{mM} \mathrm{Spm}$ resulted in a skewed distribution, reaching its maximum at $\mathrm{pH} 7.5$ (Figure $4 \mathrm{f}$ ). The reason for the different activation profiles of the $26 \mathrm{~S}$ and $20 \mathrm{~S}$ proteasomes by Spm is not completely clear at present. It is possible that the high concentration of polyamines, together with activation of the $20 \mathrm{~S}$ catalytic particle, also affects the $19 \mathrm{~S}$ regulatory particle, and therefore structurally disturbs the diffusion of the substrate into the $20 \mathrm{~S}$ particle.

A comparison of the ratio of the chymotrypsin-like activity of the $26 \mathrm{~S}$ proteasome measured in a carbonate-phosphate buffer supplemented with arginine, ornithine, Spd, or Spm to the activity of the $26 \mathrm{~S}$ proteasome measured in the carbonate-phosphate buffer alone revealed that spermine has the most pronounced ability to counteract carbonate-driven proteasome stalling at an alkaline $\mathrm{pH}(7.5-8.0)$ (Figure $4 \mathrm{~g}$ ). The most reasonable explanation for this experimental observation is deprotonation of proteasomes by carbonate ions at an alkaline $\mathrm{pH}$, leading to proteasome inhibition. If we will compare the activity of $20 \mathrm{~S}$ and $26 \mathrm{~S}$ in the anionic buffers, one may suggest that $20 \mathrm{~S}$ is less affected by these buffers and therefore the observed inhibition of the $26 \mathrm{~S}$ is rather caused by the rearrangement or dissociation of the regulatory subparticle. Spm, as a proton donor, protects proteasomes from deprotonation during simultaneous exposure to Spm and carbonate and thus preserves its activity (Figure 4h). Finally, we tested if Spm activated proteasome in terms of the protein substrates. To this end, we reconstituted the ubiquitination cascade by incubation of the recombinant $\mathrm{Ub}^{\mathrm{vv}}$-TagGFP2 with $\mathrm{E} 1$ and $\mathrm{UbcH} 5 \mathrm{c}$ ligases and further added a polyubiquitinated substrate to the $26 \mathrm{~S}$ proteasome in the presence or absence of Spm at different $\mathrm{pH}$ levels (Figure 4i). Our data revealed that the $26 \mathrm{~S}$ proteasome is inactivated at an alkaline $\mathrm{pH}$, whereas Spm restores its activity toward polyubiquitinated TagGFP2.

\section{Conclusions}

The mechanisms by which tumor cells invade are complex and may be tuned in response to altered environmental conditions [50]. Because of an enhanced glucose metabolism, proton production and excretion are generally increased in cancers [51]. This, combined with poor perfusion, results in an acidic extracellular $\mathrm{pH}$ ( $\mathrm{pHe}$ ) that is toxic for normal cells in malignant tumors ( $\mathrm{pH}$ 6.5-6.9), which is different from that of normal tissue under physiological conditions (pHe 7.2-7.4) [52]. An acidic pHe increases in vitro activity of cathepsin proteinases [15], which are generally believed to be involved in local invasion [14] and tissue remodeling [53,54]. Additionally, an acidic environment increases vascular endothelial growth factor (VEGF)-driven angiogenesis and inhibits the immune response to tumor antigens [55]. Furthermore, cancer cells exposed to a low $\mathrm{pH}$ show increased invasion, both in vitro and in vivo [56].

Cellular acidification and alkalization both shift the cellular metabolism in a manner too rapid to be explained by the delayed effects of transcriptional control [57-59]. At least part of these shifts can be explained by protonation-the most rapid and reversible post-translational modification of proteins [60]. In this study, we speculate that intracellular alkalization, common for cancer cells, may lead to impairment of proteasome function. Therefore, cancers have to increase the activity of the UPS by utilizing various extensive pathways, e.g., enhanced expression of the proteasome subunits [61]. Consumption of polyamines may represent an alternative intensive route to more active proteasomes, which do not require its elevated expression. In summary, polyamines, which are evidently essential for cancer cells in terms of the growth, invasion, and metastasis, may potentially have one more important function linked to the maintenance of proteasome activity in alkaline conditions. Inhibition of polyamine synthesis and its uptake by polyamine transporters [62] may become a clinically relevant and novel therapeutic strategy to selectively stall proteasomes in tumor cells. 
Author Contributions: A.A.K. and A.A.B.J. designed the experiments; A.A.K., G.A.S., A.N.K., V.I.V. and A.A.B.J. performed the experiments; A.A.K., P.Y.B. and A.A.B.J. analyzed the data; A.A.K. and A.A.B.J. wrote the paper. All authors have read and agreed to the published version of the manuscript.

Funding: The study was supported by the Russian Scientific Foundation, Project \#19-14-00262.

Acknowledgments: We acknowledge Ekaterina Kuzina for her valuable comments and reading the manuscript.

Conflicts of Interest: The authors declare no conflict of interest.

\section{References}

1. Talley, K.; Alexov, E. On the pH-optimum of activity and stability of proteins. Proteins 2010, 78, $2699-2706$. [CrossRef] [PubMed]

2. Gatenby, R.A.; Gillies, R.J. Why do cancers have high aerobic glycolysis? Nat. Rev. Cancer 2004, 4, 891-899. [CrossRef] [PubMed]

3. Hochachka, P.W.; Mommsen, T.P. Protons and anaerobiosis. Science 1983, 219, 1391-1397. [CrossRef] [PubMed]

4. Vander Heiden, M.G.; Cantley, L.C.; Thompson, C.B. Understanding the Warburg effect: The metabolic requirements of cell proliferation. Science 2009, 324, 1029-1033. [CrossRef] [PubMed]

5. Hanahan, D.; Weinberg, R.A. Hallmarks of cancer: The next generation. Cell 2011, 144, 646-674. [CrossRef] [PubMed]

6. Koppenol, W.H.; Bounds, P.L.; Dang, C.V. Otto Warburg's contributions to current concepts of cancer metabolism. Nat. Rev. Cancer 2011, 11, 325-337. [CrossRef]

7. Ward, P.S.; Thompson, C.B. Metabolic reprogramming: A cancer hallmark even warburg did not anticipate. Cancer Cell 2012, 21, 297-308. [CrossRef]

8. Wu, H.; Ding, Z.; Hu, D.; Sun, F.; Dai, C.; Xie, J.; Hu, X. Central role of lactic acidosis in cancer cell resistance to glucose deprivation-induced cell death. J. Pathol. 2012, 227, 189-199. [CrossRef]

9. Webb, B.A.; Chimenti, M.; Jacobson, M.P.; Barber, D.L. Dysregulated pH: A perfect storm for cancer progression. Nat. Rev. Cancer 2011, 11, 671-677. [CrossRef]

10. Gerweck, L.E.; Seetharaman, K. Cellular pH gradient in tumor versus normal tissue: Potential exploitation for the treatment of cancer. Cancer Res. 1996, 56, 1194-1198.

11. Casey, J.R.; Grinstein, S.; Orlowski, J. Sensors and regulators of intracellular pH. Nat. Rev. Mol. Cell Biol. 2010, 11, 50-61. [CrossRef] [PubMed]

12. Chiche, J.; Brahimi-Horn, M.C.; Pouyssegur, J. Tumour hypoxia induces a metabolic shift causing acidosis: A common feature in cancer. J. Cell. Mol. Med. 2010, 14, 771-794. [CrossRef] [PubMed]

13. Schulze, A.; Harris, A.L. How cancer metabolism is tuned for proliferation and vulnerable to disruption. Nature 2012, 491, 364-373. [CrossRef] [PubMed]

14. Gatenby, R.A.; Gawlinski, E.T.; Gmitro, A.F.; Kaylor, B.; Gillies, R.J. Acid-mediated tumor invasion: A multidisciplinary study. Cancer Res. 2006, 66, 5216-5223. [CrossRef] [PubMed]

15. Robey, I.F.; Baggett, B.K.; Kirkpatrick, N.D.; Roe, D.J.; Dosescu, J.; Sloane, B.F.; Hashim, A.I.; Morse, D.L.; Raghunand, N.; Gatenby, R.A.; et al. Bicarbonate increases tumor $\mathrm{pH}$ and inhibits spontaneous metastases. Cancer Res. 2009, 69, 2260-2268. [CrossRef]

16. McCarty, M.F.; Whitaker, J. Manipulating tumor acidification as a cancer treatment strategy. Altern. Med. Rev. 2010, 15, 264-272.

17. Martin, N.K.; Gaffney, E.A.; Gatenby, R.A.; Gillies, R.J.; Robey, I.F.; Maini, P.K. A mathematical model of tumour and blood pHe regulation: The HCO3-/CO2 buffering system. Math. Biosci. 2011, 230, 1-11. [CrossRef]

18. Silva, A.S.; Yunes, J.A.; Gillies, R.J.; Gatenby, R.A. The potential role of systemic buffers in reducing intratumoral extracellular $\mathrm{pH}$ and acid-mediated invasion. Cancer Res. 2009, 69, 2677-2684. [CrossRef]

19. Xie, J.; Wu, H.; Dai, C.; Pan, Q.; Ding, Z.; Hu, D.; Ji, B.; Luo, Y.; Hu, X. Beyond Warburg effect—Dual metabolic nature of cancer cells. Sci. Rep. 2014, 4, 4927. [CrossRef]

20. Russell, D.H. Clinical relevance of polyamines. Crit. Rev. Clin. Lab. Sci. 1983, 18, 261-311. [CrossRef]

21. Peters, D.; Berger, J.; Langnaese, K.; Derst, C.; Madai, V.I.; Krauss, M.; Fischer, K.D.; Veh, R.W.; Laube, G. Arginase and Arginine Decarboxylase-Where Do the Putative Gate Keepers of Polyamine Synthesis Reside in Rat Brain? PLoS ONE 2013, 8, e66735. [CrossRef] [PubMed] 
22. Tabib, A.; Bachrach, U. Activation of the proto-oncogene c-myc and c-fos by c-ras: Involvement of polyamines. Biochem. Biophys. Res. Commun. 1994, 202, 720-727. [CrossRef] [PubMed]

23. Panagiotidis, C.A.; Artandi, S.; Calame, K.; Silverstein, S.J. Polyamines alter sequence-specific DNA-protein interactions. Nucleic Acids Res. 1995, 23, 1800-1809. [CrossRef] [PubMed]

24. Childs, A.C.; Mehta, D.J.; Gerner, E.W. Polyamine-dependent gene expression. Cell. Mol. Life Sci. 2003, 60, 1394-1406. [CrossRef] [PubMed]

25. Becciolini, A.; Porciani, S.; Lanini, A.; Balzi, M.; Cionini, L.; Bandettini, L. Polyamine levels in healthy and tumor tissues of patients with colon adenocarcinoma. Dis. Colon Rectum 1991, 34, 167-173. [CrossRef]

26. LaMuraglia, G.M.; Lacaine, F.; Malt, R.A. High ornithine decarboxylase activity and polyamine levels in human colorectal neoplasia. Ann. Surg. 1986, 204, 89-93. [CrossRef]

27. Linsalata, M.; Caruso, M.G.; Leo, S.; Guerra, V.; D'Attoma, B.; Di Leo, A. Prognostic value of tissue polyamine levels in human colorectal carcinoma. Anticancer Res. 2002, 22, 2465-2469.

28. Radford, D.M.; Nakai, H.; Eddy, R.L.; Haley, L.L.; Byers, M.G.; Henry, W.M.; Lawrence, D.D.; Porter, C.W.; Shows, T.B. Two chromosomal locations for human ornithine decarboxylase gene sequences and elevated expression in colorectal neoplasia. Cancer Res. 1990, 50, 6146-6153.

29. Takenoshita, S.; Matsuzaki, S.; Nakano, G.; Kimura, H.; Hoshi, H.; Shoda, H.; Nakamura, T. Selective elevation of the N1-acetylspermidine level in human colorectal adenocarcinomas. Cancer Res. 1984, 44, 845-847.

30. Durie, B.G.; Salmon, S.E.; Russell, D.H. Polyamines as markers of response and disease activity in cancer chemotherapy. Cancer Res. 1977, 37, 214-221.

31. Farhadian, S.; Shareghi, B.; Saboury, A.A. Exploring the thermal stability and activity of alpha-chymotrypsin in the presence of spermine. J. Biomol. Struct. Dyn. 2017, 35, 435-448. [CrossRef]

32. Singh, B.P.; Saha, I.; Nandi, I.; Swamy, M.J. Spermine and spermidine act as chemical chaperones and enhance chaperone-like and membranolytic activities of major bovine seminal plasma protein, PDC-109. Biochem. Biophys. Res. Commun. 2017, 493, 1418-1424. [CrossRef]

33. Kudriaeva, A.; Kuzina, E.S.; Zubenko, O.; Smirnov, I.V.; Belogurov, A., Jr. Charge-mediated proteasome targeting. FASEB J. 2019, 33, 6852-6866. [CrossRef] [PubMed]

34. Kuzina, E.; Kudriaeva, A.; Smirnov, I.; Dubina, M.V.; Gabibov, A.; Belogurov, A., Jr. Glatiramer acetate and nanny proteins restrict access of the multiple sclerosis autoantigen myelin basic protein to the $26 \mathrm{~S}$ proteasome. Biomed. Res. Int. 2014, 2014, 926394. [CrossRef] [PubMed]

35. Belogurov, A., Jr.; Kudriaeva, A.; Kuzina, E.; Smirnov, I.; Bobik, T.; Ponomarenko, N.; Kravtsova-Ivantsiv, Y.; Ciechanover, A.; Gabibov, A. Multiple sclerosis autoantigen myelin basic protein escapes control by ubiquitination during proteasomal degradation. J. Biol. Chem. 2014, 289, 17758-17766. [CrossRef] [PubMed]

36. Kuzina, E.S.; Chernolovskaya, E.L.; Kudriaeva, A.A.; Zenkova, M.A.; Knorre, V.D.; Surina, E.A.; Ponomarenko, N.A.; Bobik, T.V.; Smirnov, I.V.; Bacheva, A.V.; et al. Immunoproteasome enhances intracellular proteolysis of myelin basic protein. Dokl. Biochem. Biophys. 2013, 453, 300-303. [CrossRef] [PubMed]

37. Ciechanover, A. Intracellular protein degradation: From a vague idea thru the lysosome and the ubiquitin-proteasome system and onto human diseases and drug targeting. Cell Death Differ. 2005, 12, 1178-1190. [CrossRef] [PubMed]

38. Kudriaeva, A.A.; Belogurov, A.A. Proteasome: A Nanomachinery of Creative Destruction. Biochemistry 2019, 84, S159-S192. [CrossRef]

39. Hideshima, T.; Richardson, P.; Chauhan, D.; Palombella, V.J.; Elliott, P.J.; Adams, J.; Anderson, K.C. The proteasome inhibitor PS-341 inhibits growth, induces apoptosis, and overcomes drug resistance in human multiple myeloma cells. Cancer Res. 2001, 61, 3071-3076.

40. Jones, C.L.; Tepe, J.J. Proteasome Activation to Combat Proteotoxicity. Molecules 2019, 24, 2841. [CrossRef]

41. Tanaka, K.; Ii, K.; Ichihara, A.; Waxman, L.; Goldberg, A.L. A high molecular weight protease in the cytosol of rat liver. I. Purification, enzymological properties, and tissue distribution. J. Biol. Chem. 1986, 261, 15197-15203. [PubMed]

42. Mellgren, R.L. Interaction of human erythrocyte multicatalytic proteinase with polycations. Biochim. Biophys. Acta 1990, 1040, 28-34. [CrossRef]

43. Yoo, S.J.; Seol, J.H.; Kang, M.S.; Chung, C.H. Poly-L-lysine activates both peptide and ATP hydrolysis by the ATP-dependent HslVU protease in Escherichia coli. Biochem. Biophys. Res. Commun. 1996, 229, 531-535. [CrossRef] 
44. Pichler, A.; Knipscheer, P.; Oberhofer, E.; Van Dijk, W.J.; Korner, R.; Olsen, J.V.; Jentsch, S.; Melchior, F.; Sixma, T.K. SUMO modification of the ubiquitin-conjugating enzyme E2-25K. Nat. Struct. Mol. Biol. 2005, 12, 264-269. [CrossRef] [PubMed]

45. Brzovic, P.S.; Lissounov, A.; Christensen, D.E.; Hoyt, D.W.; Klevit, R.E. A UbcH5/ubiquitin noncovalent complex is required for processive BRCA1-directed ubiquitination. Mol. Cell 2006, 21, 873-880. [CrossRef] [PubMed]

46. Kisselev, A.F.; Akopian, T.N.; Castillo, V.; Goldberg, A.L. Proteasome active sites allosterically regulate each other, suggesting a cyclical bite-chew mechanism for protein breakdown. Mol. Cell 1999, 4, 395-402. [CrossRef]

47. Orlowski, M. Selective activation of the $20 \mathrm{~S}$ proteasome (multicatalytic proteinase complex) by histone h3. Biochemistry 2001, 40, 15318-15326. [CrossRef]

48. Basset, G.; Raymond, P.; Malek, L.; Brouquisse, R. Changes in the expression and the enzymic properties of the $20 \mathrm{~S}$ proteasome in sugar-starved maize roots. evidence for an in vivo oxidation of the proteasome. Plant Physiol. 2002, 128, 1149-1162. [CrossRef]

49. Gross, E.; Kurtz, I. Structural determinants and significance of regulation of electrogenic $\mathrm{Na}^{+}-\mathrm{HCO}_{3}{ }^{-}$ cotransporter stoichiometry. Am. J. Physiol. Ren. Physiol. 2002, 283, F876-F887. [CrossRef]

50. Friedl, P.; Wolf, K. Tumour-cell invasion and migration: Diversity and escape mechanisms. Nat. Rev. Cancer 2003, 3, 362-374. [CrossRef]

51. Schornack, P.A.; Gillies, R.J. Contributions of cell metabolism and $\mathrm{H}^{+}$diffusion to the acidic $\mathrm{pH}$ of tumors. Neoplasia 2003, 5, 135-145. [CrossRef]

52. Stubbs, M.; McSheehy, P.M.; Griffiths, J.R.; Bashford, C.L. Causes and consequences of tumour acidity and implications for treatment. Mol. Med. Today 2000, 6, 15-19. [CrossRef]

53. Chambers, A.F.; Matrisian, L.M. Changing views of the role of matrix metalloproteinases in metastasis. J. Natl. Cancer. Inst. 1997, 89, 1260-1270. [CrossRef]

54. Gatenby, R.A.; Gawlinski, E.T. A reaction-diffusion model of cancer invasion. Cancer Res. 1996, 56, 5745-5753. [PubMed]

55. Lardner, A. The effects of extracellular pH on immune function. J. Leukoc. Biol. 2001, 69, 522-530.

56. Moellering, R.E.; Black, K.C.; Krishnamurty, C.; Baggett, B.K.; Stafford, P.; Rain, M.; Gatenby, R.A.; Gillies, R.J. Acid treatment of melanoma cells selects for invasive phenotypes. Clin. Exp. Metastasis 2008, 25, 411-425. [CrossRef]

57. Kaminskas, E. The pH-dependence of sugar-transport and glycolysis in cultured Ehrlich ascites-tumour cells. Biochem. J. 1978, 174, 453-459. [CrossRef]

58. Ismail-Beigi, F.; Mercado, C.L.; Loeb, J.N. Stimulation of glucose transport in Clone 9 cells by exposure to alkaline pH. Am. J. Physiol. 1990, 258, C327-C335. [CrossRef]

59. Wohlhueter, R.M.; Plagemann, P.G. Hexose transport and phosphorylation by Novikoff rat hepatoma cells as function of extracellular pH. J. Biol. Chem. 1981, 256, 869-875.

60. Schonichen, A.; Webb, B.A.; Jacobson, M.P.; Barber, D.L. Considering protonation as a posttranslational modification regulating protein structure and function. Annu. Rev. Biophys. 2013, 42, 289-314. [CrossRef]

61. Kumatori, A.; Tanaka, K.; Inamura, N.; Sone, S.; Ogura, T.; Matsumoto, T.; Tachikawa, T.; Shin, S.; Ichihara, A. Abnormally high expression of proteasomes in human leukemic cells. Proc. Natl. Acad. Sci. USA 1990, 87, 7071-7075. [CrossRef] [PubMed]

62. Chen, Y.; Weeks, R.S.; Burns, M.R.; Boorman, D.W.; Klein-Szanto, A.; O'Brien, T.G. Combination therapy with 2-difluoromethylornithine and a polyamine transport inhibitor against murine squamous cell carcinoma. Int. J. Cancer 2006, 118, 2344-2349. [CrossRef] [PubMed]

Publisher's Note: MDPI stays neutral with regard to jurisdictional claims in published maps and institutional affiliations. 